\title{
The World Energy Coalition and the Global Energy Charter
}

$\mathrm{T}$ here cannot be many thinking individuals left today who do not accept the critical role that energy plays in the complex interaction between human development and environmental change. There can be even fewer who do not accept that energy and development policies can not be allowed to continue as formerly if the future of three-quarters of the human population is to be improved and disastrous damages to the environment affecting all of us are to be avoided.

We who have gathered here to examine the potential and problems of new and futuristic energy technologies are more fortunate than our pioneering forefathers whose solutions are proving to be increasingly unsustainable. Unlike them, we are able to analyse data and experience of the last 200 years to assess the impacts of policies and technologies upon human society. The impacts upon ecological balances, which physically abound in our daily lives, are often difficult to predict to such quantitative accuracies as some policymakers demand before they are prepared to risk popular votes. In spite of these uncertainties, however, the techno-economic establishment undoubtedly has knowledge, resources, and tools, to introduce changes which could slow down global ecological damage in the short and medium terms and simultaneously promote sustainable development of the energy-starved Poor World. Unfortunately it is highly uncertain whether possession of knowledge will be matched by wisdom of choice and action such as could steer the world towards a more balanced future.

It appears to us that, in this period of uncertainty, individuals - especially those who work in the sphere of generation and application of knowledge - have to reorientate their roles. Firstly they have to learn to examine every application of new technology on the basis of the totality of its impact. This implies a rigorous internal process of critical assessment of new technologies before they are handed over to market forces. Secondly they have to 'come down from their ivory towers and out of their back rooms' and actively participate in the roughand-tumble of popular discussions at appropriate social and political levels. The selling of ideas and concepts to the wider masses has to become a part of our professonal work, and all legitimate tools of a democratic society have to be used to make a sale of hard options to politicians, industrialists, and housepersons.

The World Energy Coalition is the start of a movement to mobilize the knowledgeable scientific, engineering, and financial, communities working in the fields of energy, ecology, and development, to strive actively for the goals of the June 1992 United Nations Conference on Environment \& Development (UNCED), which has become crucial as the starting shot in a race against time. The Global Energy Charter has been formulated in order to focus on these goals in a concentrated manner. It provides a framework for policymaking in the energy sector at both national and international levels, and for timely implementation of sustainable programmes. It is a tool to be used not just to push for sensible results at UNCED in Brazil but to encourage a subsequent worldwide shift in energy and development policies. Most of all, it is a powerful mechanism for regular monitoring of progress by the United Nations, governments, nongovernmental organizations, and concerned individuals.

\section{The World Energy Coalition,}

Considering the crucial role which energy plays in world-wide economic and social development;

Taking into account the necessity to increase energy services particularly in developing countries;

Wishing to mitigate and where possible prevent adverse local and global impacts of energy generation, transmission, and use, on human health and the environment, including all living species;

Noting especially the climate implications of increased atmospheric concentrations of 'greenhouse' gases as established by UNEP, WMO/IPCC, and WHO;

Noting further the thrust of the deliberations of the International Negotiating Committee on Climate Change; Proposes that the Global Energy Charter be adopted at the United Nations Conference on Environment and Development (UNCED) in conjunction with the Earth Charter and Agenda 21; and

Proposes further that international negotiations begin with an International Climate and Energy Convention.

The Global Energy Charter has four main objectives:

a) to act as a framework for a world energy strategy aimed at concerted international, regional, and national, programmes for harmonious and sustainable economic and social development to ensure the survival of living species;

b) to urge governments to give rational use of energy, energy efficiency, and renewable, clean, safe, and sustainable, energy technologies the highest priority in national, regional, and international, development and implementation programmes on a scale comparable to the former US Man-to-the-Moon programme;

c) to promote a plan of action to ensure that the services which energy can supply are adequately available to all human beings to satisfy their development needs; and

d) to propose the establishment of an international energy organization dedicated to the achievement of the Charter's objectives, through, amongst other measures, research, development, and commercialization, of 
relevant technologies, information exchange, training, consultancy, programme monitoring, and mobilization of adequate financial resources.

The Global Energy Charter for sustainable energy policies includes the following main points:

1 - The setting up of targets for energy-related emission limits and performance standards for energy products and systems.

2 - The establishment of guidelines and internationally standardized methodologies of calculation for determining external effects and life-cycle costs for all energy systems, taking into account environmental, health, and other, damages caused by energy-related activities.

3 - The establishment of global, regional, national, and local, strategies and plans for energy efficiency improvements, safety controls, waste management, and emissions reductions, in the production, storage, transportation, and use, of all types of energy.

4 - The establishment of global, regional, national, and local, programmes for the substitution of polluting and exhaustible energy sources by environmentally less harmful, sustainable, energy technologies.

5 - Based on guidelines under point 2 , the introduction of a system of full cost-pricing coupled with a system for compensation of external damages from all energy-related activities, not forgetting waste disposal and decommissioning, to reflect the total social and environmental cost.

6 - The creation of dedicated energy funds, one of them to be called the Climate and Energy Fund, allocated from external cost levies and other sources, for the financing of energy efficiency improvements and best available environmentally sound energy technologies, with special arrangements for countries which would not otherwise be able to introduce such measures.

7 - The promotion and monitoring of strategies and implementation programmes under the Global Energy Charter, and the development of new financial instruments and investment mechanisms, involving both the public and private sectors in synergy with each other.

8 - The promotion of exchange of technology, know-how, education, training programmes, information, statistics, and data on best available environmentally sound energy technologies, environmentconscious human behaviour, energy efficiency and saving, performance standards, and safety codes as well as relative and absolute energy costs.

\author{
HARI N. SHARAN, Chairman \\ World Energy Coalition \\ President of Dasag Energy Engineering \\ Birchstrasse 6 \\ 8472 Seuzach \\ Switzerland, \\ \& \\ Gustav R. Grob, President \\ Cercle Mondial du Consensus \\ Secretary-General of the World Clean Energy Conference \\ CMDC Central Secretariat \\ Kellerweg 38 \\ 8055 Zürich \\ Switzerland.
}

